\title{
Esophageal Cancer by AJCC v6 Stage
}

National Cancer Institute

\section{Source}

National Cancer Institute. Esophageal Cancer by AJCC v6 Stage. NCI Thesaurus. Code C90500.

A term that refers to the staging of esophageal carcinoma according to the American Joint Committee on Cancer, 6th edition. 